\title{
Influence of topography on in situ stress parameter at the proposed powerhouse sites of Rupaligad re-regulating project, Nepal
}

\author{
DS Subrahmanyam, G Shyam, K Vamshidhar and S Vikram \\ National Institute of Rock Mechanics \\ Bengaluru, India \\ subbu3268@gmail.com
}

\begin{abstract}
In-situ stress parameters of the rock mass are one of the vital inputs for the design of any large underground openings. In general, the in-situ stress magnitude and orientation are influenced by topography, and major geological structures like folds, faults and intrusions. These structures bring about local heterogeneities in rocks, thus leading to change in orientation of stress trajectories. In this paper we would like to present a case study about the influence of topography/ valley on in situ stress measurements carried out at a hydroelectric project site. The stress measurements were carried out by HTPF method on both left and right banks of the river at the proposed powerhouse sites. The test site/borehole location of left bank is in close proximity to valley compared to its counterpart. The (in-situ stress) major horizontal principal stress direction of the rock mass is $\mathbf{N} \mathbf{2 0}^{\circ}$ and $\mathrm{N} 130^{\circ}$ at right and left banks respectively. It is inferred that the horizontal stresses might have been relaxed due to the absence of influence of topography on the right bank whereas the direction of in-situ stress tensor at the left bank might be perturbed by topography due to the close proximity of the valley.
\end{abstract}

Keywords-Hydraulic testing on pre-existing fractures (HTPF); Stress; Powerhouse; Maximum compression; Topography;

\section{INTRODUCTION}

Rupali Gad re-regulating dam is conceived along the river Mahakali in Nepal, as an integral component of Pancheshwar Multipurpose Project (PMP). It is located (Fig. 1) about $25 \mathrm{~km}$ downstream from Pancheshwar high dam. The objective of the project is to minimise social and environmental impacts due to high fluctuation of water level and flow in downstream when high dam power plants operate at peaking load. The project envisages construction of $83 \mathrm{~m}$ high concrete gravity dam and two underground powerhouses on both left and right banks with installed capacity of $240 \mathrm{MW}$ each.

It is always desirable to carry out in-situ stress measurement in such huge underground openings for designing of the support types as the stability of the cavern gets enhanced if the long axis of the cavern is oriented along or sub-parallel to that of maximum principal stress.

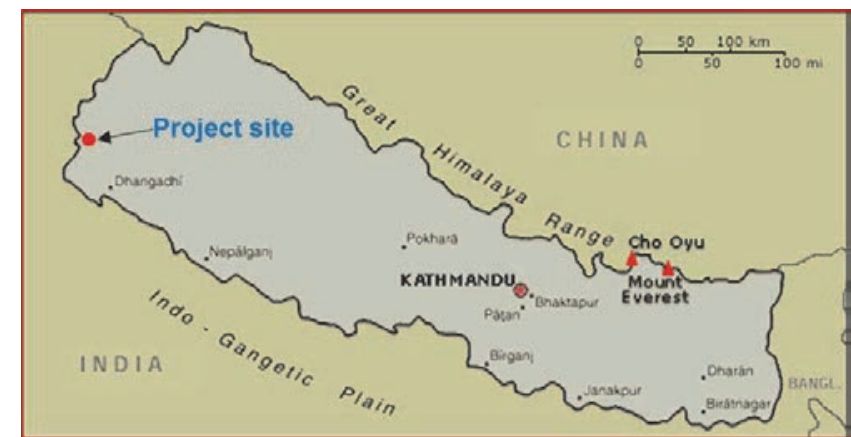

Fig. 1. Location of the project site

Water and Power Consultancy Service (WAPCOS) India Ltd. has been entrusted to prepare the Detailed Project Report (DPR) of Rupali Gad re-regulating dam by the Pancheshwar Development Authority for finalizing the design, cost and schedule of construction of this project. In view of the above WAPCOS India Ltd engaged National Institute of Rock Mechanics (NIRM) India, to carryout insitu stress investigations at the proposed Powerhouse project sites. In-situ stress measurements were conducted by Hydraulic testing on pre-existing fractures (HTPF) method in NX size borehole on both left and right banks of the river at the proposed powerhouse sites and analysis of the data using software to evaluate complete stress tensors.

\section{REGIONAL GEOLOGY}

The rock mass encountered at proposed power house cavern is moderately strong to strong quartzite with intercalary weaker bands of garnetiferrous mica schist. These schist bands may form significant horizons of relatively weaker strength for a thickness of up to $10 \mathrm{~m}$. They are riddled sometimes with thin bedding/foliation shears. Presence of fractured siliceous permeations and bounding structures in rock mass is indicative of operative deformational stresses. The rock mass characterization so attained in Quartzite is indicative of RMR values of 45 to 60 (Fair to Good rock). In respect of Garnetiferrous Mica schist/Mica schist, it varies between RMR 30 to 47 (Poor to Fair rock). Rock strata exposed at the project site is shown in Fig. 2. 


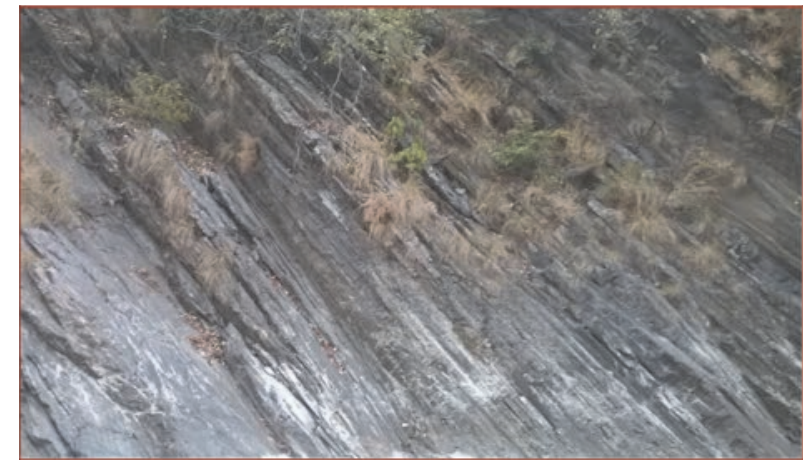

Fig. 2. Rock strata exposed at the project site

\section{A. Local geology at the powerhouse site}

Rupaligad Dam site is located on 'Dhalidhura Klippe'. The rocks belonging to Almora Crystalline Group are exposed at the site. The surface geological attributes have been defined based on Geological mapping of Dam site on 1:1000 scale. The sub -surface exploration has been conducted resorting to 21 drill holes (Aggregate length $1428.89 \mathrm{~m}$ ) and two numbers of drifts (Total length $50 \mathrm{~m}$ ). Grey coloured fine to medium grained, feebly weathered and fresh mica schist with thin bands of quartzite have been mapped between the area $170 \mathrm{~m}$ upstream and $300 \mathrm{~m}$ downstream of the dam axis. A small patch of graphite schist has been recorded on the left abutment. The left abutment has a continuous exposure of rocks up to an elevation of 445 $\mathrm{m}$, above which it remains concealed under a thin cover of over burden comprising debris material admixed with soil. The rocks on right abutment mostly remain under variable thickness of over burden cover. The light coloured quartzite bands are of variable thickness (10 to $75 \mathrm{~cm})$ and occasionally pinch out along the up slope direction. The mica schist with thin quartzite bands are monotonously exposed in the area with foliation striking NW-SE dipping by $30^{\circ}$ to $50^{\circ}$ north eastward i.e. favourable towards upstream. These would provide almost uniform foundation rock for the dam, excepting the patches occupied by lensoids of graphite schists. The rock is generally fresh below the over burden which generally varies between $1 \mathrm{~m} \& 5 \mathrm{~m}$. The mica schist with quartzite was encountered below the overburden in the drill holes. In Rupaligad reservoir, which is located over Lesser Himalayan rocks, seven landslide incidences were noticed. Out of these, only a couple of slides are located close to the reservoir rim or the Full Reservoir Level (FRL).

\section{TECHNICAL BOREHOLE DATA}

Two vertical boreholes of NX size were drilled on both left and right banks over the proposed powerhouse location up to 150 meters depth to carryout stress measurement. The important technical borehole data are summarized in Table I.

\section{DETERMINATION IN-SITU STRESS PARAMETERS}

Hydraulic fracturing method is intended for the determination of in-situ stress in an NX size borehole at desired locations, normally consisting of three or more zones at different depths. For determination of stress at greater depths, the zones can be decided accordingly to the site specific requirements. Results of the stress measurement program provide the magnitude of the principal stresses as well as the direction of maximum horizontal principal stress.

TABLE I. TECHNICAL BOREHOLE DATA

\begin{tabular}{|l|l|l|l|}
\hline $\begin{array}{l}\text { Borehole } \\
\text { No./Location }\end{array}$ & Direction & $\begin{array}{l}\text { Borehole } \\
\text { diameter }\end{array}$ & $\begin{array}{l}\text { Depth of } \\
\text { borehole }\end{array}$ \\
\hline $\begin{array}{l}\text { BH 21/Right } \\
\text { bank }\end{array}$ & Vertical down & NX $(76 \mathrm{~mm})$ & $150 \mathrm{~m}$ \\
\hline $\begin{array}{l}\text { BH 24/Left } \\
\text { bank }\end{array}$ & Vertical down & NX $(76 \mathrm{~mm})$ & $150 \mathrm{~m}$ \\
\hline
\end{tabular}

\section{A. Equipment}

The hydraulic fracture assembly with steel reinforced packer elements with $67 \mathrm{~mm}$ OD (Fig. 3) was used for fracture initiation and extension. The length of each packer element was about $400 \mathrm{~mm}$. The test interval length was 350 $\mathrm{mm}$.

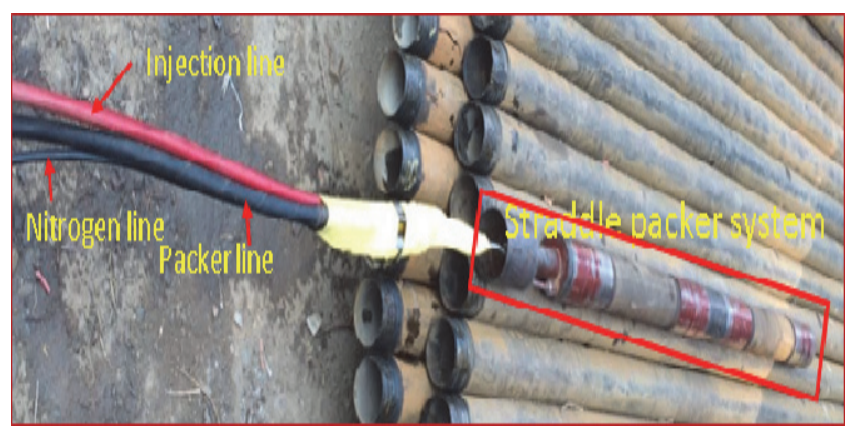

Fig. 3. Hydraulic fracturing tool

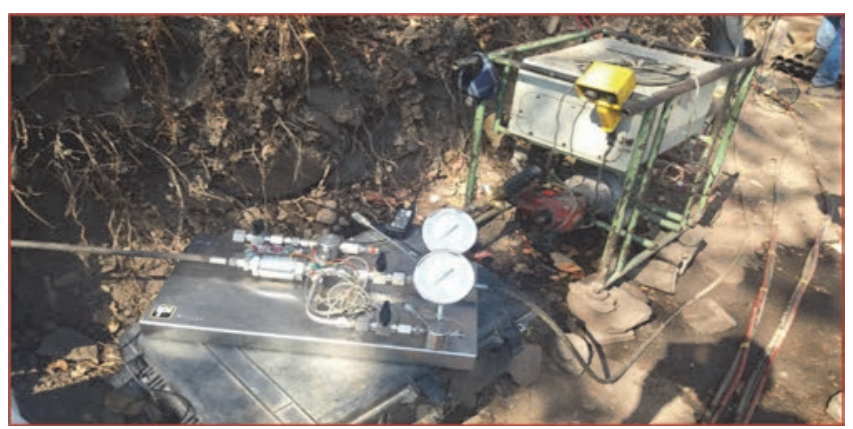

Fig. 4. Control panel \& high pressure pump

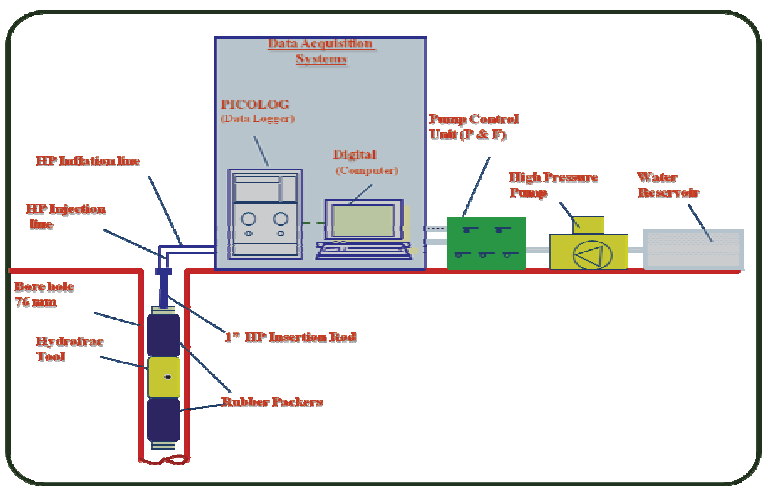

Fig. 5. Line diagram of hydraulic fracture test setup

High pressure inflation tube (max. operating pressure 52 
$\mathrm{MPa}$ ) was used for packer inflation. The maximum injection rate of the electric pump was $10 \mathrm{l} / \mathrm{min}$ (Fig. 4) using water for pressurisation. Packer and interval pressures were monitored by pressure gauges. Data was stored digitally in laptop through a data acquisition interface called PICO logger. The line diagram of the hydraulic fracture test setup is shown in Fig. 5.

\section{B. Investigation procedure}

After the hydraulic fracture assembly was positioned at a pre-determined test section (selected on the basis of core inspection), the injection pressure was increased until a hydraulic fracture was initiated or a pre-existing fracture was reopened. Subsequently, two to three refrac-cycles were conducted. Between the injection cycles the system was vented. The back flow from the fracture into the interval section was observed by short valve closures during the venting phase. Finally, the packers were deflated and the tool was moved to the next test section. After all the hydraulic fracturing tests were conducted in the borehole, an impression packer tool with a soft rubber skin was run into the holes to obtain information on the orientation of the induced or opened fracture traces at the borehole wall.

\section{- Left bank}

In the left bank BH-24 borehole, six zones were selected on the basis of core inspection. The stress measurements were conducted in all the six zones from 45 to $150 \mathrm{~m}$ depth. The lowering and hoisting of the hydraulic fracture tool, execution of the test and Impression packer tool are given in Fig. 6 \& Fig. 7.

\section{- $\quad$ Right bank}

In right bank $\mathrm{BH}-21$ borehole, five zones were selected on the basis of core inspection. The stress measurements were conducted in all the five zones from 30 to $150 \mathrm{~m}$ depth.

The determination of shut-in-pressure is straight forward when a sharp break occurs after the fast pressure decline following pump shut off. The shut-in-pressure is calculated from the last cycle of the pressure-time curve.

\section{Stress evaluation procedure and results}

Determination of in-situ stress inside the borehole of the proposed power house was conducted with the following test situations:

\section{- $\quad$ Pronounced topography}

- Presence of anisotropic rock

Due to the above aspects, a medium to large scatter in fracture orientation data was noticed which negated the use of classical simple hydraulic fracture hypothesis suggested by Hubert and Wills [2]. Therefore the data analysis required a more sophisticated method, namely the interpretation of measured normal stress acting across arbitrary oriented fracture planes.

In this method the shut-in pressure (Psi) is used to measure the normal stress component under the assumption that the vertical is a principal stress axis and the vertical stress $\sigma \mathrm{v}$ is equal to the weight of the overburden.

The determination of shut-in-pressure is straight forward when a sharp break after the fast pressure decline following pump shut off. We calculated the shut-in-pressure from the third cycle of the pressure-time curve. Table II \& III provides the final stress tensors as derived from two boreholes at left and right bank.

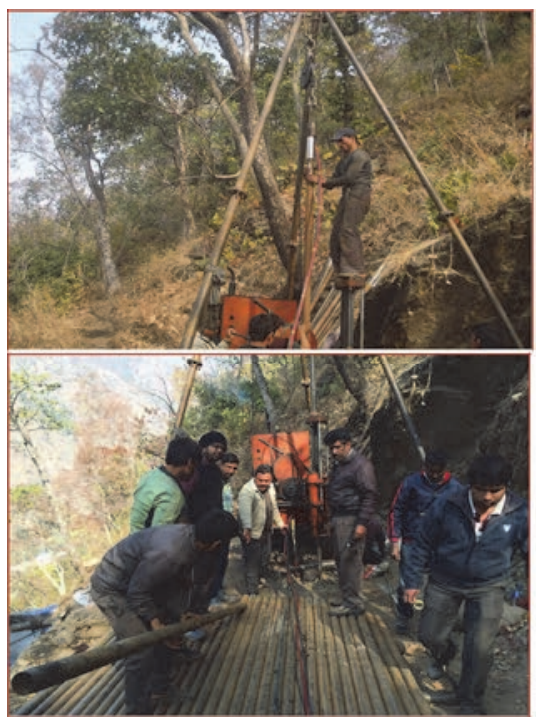

Fig. 6. Lowering \& hoisting of hydraulic fracture equipment with NQ rods

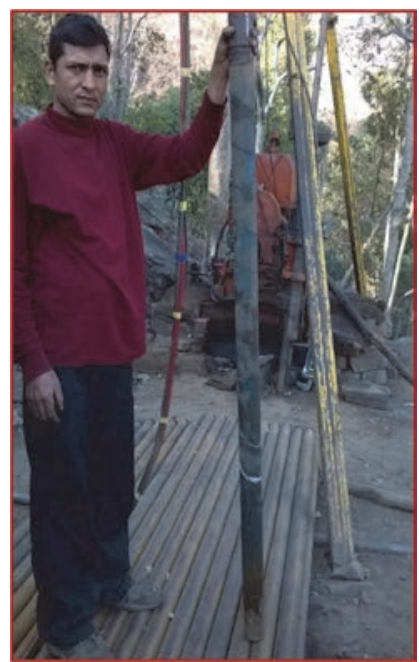

Fig. 7. Impression packer tool

\section{DISCUSSION AND CONCLUSION}

A sophisticated data interpretation method viz. Psi (shutin-pressure) method was used in the analysis program GENSIM. The code GENSIM VI.1 computes the stress field on the basis of measured shut-in pressure and fracture orientation data. Assumption: Homogeneous stress field, overburden is a principal stress which is equal to overburden pressure.Maximum horizontal principal stress direction measured for left bank is N1300 \& for right bank is N200. The horizontal stresses at right bank might have been relaxed 
due to absence of influence of topography. While the direction of in-situ stress tensor N1300 measured at the left bank might have been perturbed by topography due to close proximity of the valley (' $U$ ' shaped valley in this case, Fig. 8)

TABLe II In-Situ Stress Tensor of the Rock Mass - Left BanK

\begin{tabular}{|l|l|}
\hline Principal stresses & Value \\
\hline $\begin{array}{l}\text { Vertical stress }\left(\sigma_{\mathrm{v}}\right) \text { in } \mathrm{MPa}(\text { test section depth } \\
=150 \mathrm{~m} \text {; density of rock }=2.7 \mathrm{gm} / \mathrm{cc})\end{array}$ & 4.05 \\
\hline $\begin{array}{l}\text { Maximum horizontal principal stress }\left(\sigma_{\mathrm{H}}\right) \text { in } \\
\mathrm{MPa}\end{array}$ & $9.95 \pm 0.3617$ \\
\hline $\begin{array}{l}\text { Minimum horizontal principal stress }\left(\sigma_{\mathrm{h}}\right) \text { in } \\
\mathrm{MPa}\end{array}$ & $3.98 \pm 0.1447$ \\
\hline $\begin{array}{l}\text { Maximum horizontal principal stress } \\
\text { direction }\end{array}$ & $\mathrm{N} 130^{0}$ \\
\hline $\mathrm{K}=\sigma_{\mathrm{H}} / \sigma_{\mathrm{v}}$ & 2.45 \\
\hline
\end{tabular}

TABLE III IN-SITU STRESS TENSOR OF THE ROCK MASS-RIGHT BANK

\begin{tabular}{|l|l|}
\hline Principal stresses & Value \\
\hline $\begin{array}{l}\text { Vertical stress }\left(\sigma_{\mathrm{v}}\right) \text { in MPa (test section depth } \\
=150 \mathrm{~m} \text {; density of rock }=2.7 \mathrm{gm} / \mathrm{cc})\end{array}$ & 4.05 \\
\hline $\begin{array}{l}\text { Maximum horizontal principal stress }\left(\sigma_{\mathrm{H}}\right) \text { in } \\
\mathrm{MPa}\end{array}$ & $7.21 \pm 1.1916$ \\
\hline $\begin{array}{l}\text { Minimum horizontal principal stress }\left(\sigma_{\mathrm{h}}\right) \text { in } \\
\mathrm{MPa}\end{array}$ & $4.81 \pm 0.7944$ \\
\hline $\begin{array}{l}\text { Maximum horizontal principal stress } \\
\text { direction }\end{array}$ & $\mathrm{N} 20^{0}$ \\
\hline $\mathrm{K}=\sigma_{\mathrm{H}} / \sigma_{\mathrm{v}}$ & 1.78 \\
\hline
\end{tabular}

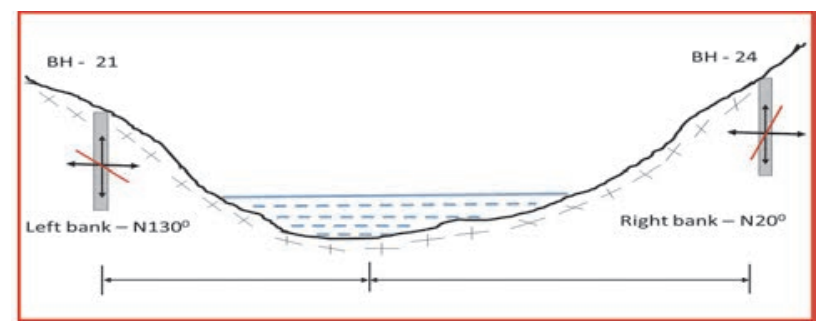

Fig. 8. U shaped valley effect

The direction of $\sigma \mathrm{H}$ N1300 in left bank may be due to following reasons:

- Valley effect: A valley in this type of topography modifies the maximum stress direction and nature of stress. Further explanations regarding valley effect are given below:

- The effect of gravity loading and tectonic loading in a valley portion contribute tensile stresses in valley bottoms. It is generally found that there is usually a zone near the valley surface in which rock mass is loose and discontinuous [4].

\section{ACKNOWLEDGEMENTS}

The author is thankful to the management and ground staffs at the test sites of Rupaligad re-regulating project, WAPCOS India ltd. for their co-ordination and concentrated efforts. Author is also thankful to Director, NIRM, for providing valuable suggestions \& permission to publish this paper.

\section{REFERENCES}

[1] F.H. Cornet, "Stress determination from hydraulic tests on pre-exiting fractures - the HTPF method". Proc. Intl Symp, Rock Stress and Rock Stress Measurements, CENTEK Publ., Lulea, pp. 301-311, 1986.

[2] K.M. Hubbert and D.G. Willis, "Mechanics of Hydraulic Fracturing", Petroleum Transactions AIME, Vol.210, T.P. 4597. Pp 153-166, 1957.

[3] Internal reports and communications.

[4] J.L. Knill, "Geotechnical significance of some glacially induced rock discontinuities". Bull. Assoc. Eng. Geol; 5, pp 49-62, 1968.

[5] MeSy's Hydraulic fracture pressure and flow rate data analysis software user's manual, 1992. 